artelogie

\section{Artelogie}

Recherche sur les arts, le patrimoine et la littérature de l'Amérique latine

$4 \mid 2013$

Fêtes et célébrations en Amérique latine

\title{
Dinâmicas Culturais Etnogênicas em Performances Identitárias : a festa dos Chiquitano
}

Leandro Mendes Rocha e Heloisa Selma Fernandes Capel

\section{(2) OpenEdition \\ Journals}

\section{Edição electrónica}

URL: https://journals.openedition.org/artelogie/6301

DOI: 10.4000/artelogie.6301

ISSN: $2115-6395$

\section{Editora}

Association ESCAL

Refêrencia eletrónica

Leandro Mendes Rocha e Heloisa Selma Fernandes Capel, «Dinâmicas Culturais Etnogênicas em Performances Identitárias : a festa dos Chiquitano», Artelogie [Online], 4 | 2013, posto online no dia 02 fevereiro 2013, consultado o 01 dezembro 2021. URL: http://journals.openedition.org/artelogie/6301; DOI: https://doi.org/10.4000/artelogie.6301

Este documento foi criado de forma automática no dia 1 dezembro 2021.

Association ESCAL 


\title{
Dinâmicas Culturais Etnogênicas em Performances Identitárias : a festa dos Chiquitano
}

\author{
Leandro Mendes Rocha e Heloisa Selma Fernandes Capel
}

1 Era o ano de 2009, no mês de junho, quando foi inaugurado o Memorial Espírito Santo dos Chiquitano em uma comunidade indígena habitante na região de fronteira do Brasil com a Bolívia. A festa de inauguração contou com forte participação dos índios Chiquitano. Foram organizadas apresentações culturais e celebrada uma missa na qual as crianças cantaram hinos em Chiquitano e os adultos tocaram caixa (tambor) e flauta, num ritmo similar aos executados nas missões Chiquitanas da Bolívia. Foram rezadas as orações do Pai Nosso, Ave Maria e Santa Maria no idioma Chiquitano. Essas orações, a pedido dos jovens daquela comunidade indígena, foram transcritas de publicações bolivianas e adaptadas para o alfabeto experimental Chiquitano brasileiro. No dizer de Santana (2012) pela primeira vez, em muitos anos, a língua Chiquitano era falada em público no lado brasileiro da fronteira. Nesse evento, os participantes da cerimônia apresentaramse com cocares de penas, adornos trançados de palha de buriti, colares de sementes e pintura corporal de argila e carvão. 0 tocador portava em seu pescoço um crucifixo demonstrando a forte presença da religiosidade típica das missões jesuíticas que deram origem aquele povo. Esses elementos foram exibidos ao público como "sinais externos" diacríticos a serem reconhecidos por todos os presentes. A pesquisadora Áurea Santana descreveu com ênfase, o evento. Segundo a autora, a percepção era de autencidade identitária, de importância normativa, afetiva e valorativa (SANTANA, 2012 : p. 55/56). Algo incomum a um povo sujeito a segregações diversas e que naquele momento, com uma performance em ato, (re)vivia social e políticamente, valores comuns continuamente modificados por conjunturas adversas.

2 Em Mato Grosso, na Terra Indígena Portal do Encantado, na região da fronteira entre o Brasil e a Bolívia, uma população de origem boliviana reivindicava para si a condição de índios Chiquitano. Esses indígenas viviam naquele momento histórico um processo de retomada meteórica de suas tradições passando de uma identidade genérica de 
camponeses cristianizados à de índios brasileiros. Na inauguração do Memorial, retomavam e/ou reinventavam suas tradições. Concorreu fortemente para esse processo, o papel exercido pela Escola Indígena e o agency das lideranças indígenas em suas estratégias políticas de retomada de uma identidade indígena por meio do ensino e utilização da língua Chiquitano pela comunidade.

3 A Escola é mantida pelo estado do Mato Grosso, com professores Chiquitano contratados para ministrar aulas, diretor, secretário, auxiliar de limpeza e merendeira recrutados na comunidade. As aulas ocorrem em salas improvisadas em um barracão de palha e nas dependências do Memorial. Essa escola havia promovido levantamentos junto aos anciãos "lembradores da língua" de itens lexicais relacionados a nomes de plantas, animais, partes do corpo humano, dentre outros. Buscava assim criar contextos socioculturais que pudessem estimular o uso da língua Chiquitano. Foram elaborados jogos que estimulavam os alunos na utilização da língua indígena. Além dos jogos foram incentivadas encenações de histórias e outras apresentações orais de forma a trazer vitalidade e visibilidade ao processo de valorização do uso da língua Chiquitano. A encenação de histórias contadas pelos mais velhos e o aprendizado das musicas utilizadas pelos Chiquitanos bolivianos tornaram-se importantes na construção das memórias coletivas que concorreram para recuperar o orgulho étnico daquele povo (SANTANA, 2012 : p. 213).

Os Chiquitanos se caracterizam por serem em sua grande maioria desterritorializados, migrantes e sofrerem dupla discriminação: se considerarem índios e estrangeiros no Brasil. Um aspecto importante é o fato de serem povos habitantes de espaços transnacionais, fronteiriços e limítrofes por excelência, portanto, habitantes de locais menos homogeneizados, podendo assim ser considerados como híbridos. Esses índios vivem, portanto, em uma região transnacional entre o Brasil e a Bolívia, fruto do amálgama de diversos grupos étnicos que foram reunidos em aldeamentos (missiones jesuíticas) entre os séculos XVII e XVIII. Uma parcela majoritária vive na Bolívia (Chiquitania) e os demais nos estados brasileiros do Mato Grosso e Mato Grosso do Sul. No dizer de Silva (2009) traços culturais, relações intergrupais, transações de bens e serviços entre as comunidades, além de rituais religiosos cristãos originários de uma herança colonial comum, estruturam as relações intercomunitárias dos Chiquitano. Os indígenas habitantes do lado brasileiro da fronteira quase não falam mais o idioma Chiquitano, muitas das tradições indígenas se perderam no tempo (carnavalito, festas religiosas católicas e conhecimentos tradicionais indígenas). Esse povo viveu um longo período de invisibilização, embora haja referencias a esses índios na região desde o século XVIII. Nos anos 1990, a FUNAI enviou técnicos à área e organizou Grupos de Trabalho visando o reconhecimento oficial desses indígenas tidos pela população regional como "bugres" ou simples camponeses. Quando da construção do Gasoduto Bolívia-Mato Grosso novamente a FUNAI foi instada a se manifestar no Estudo de Impacto Ambiental referente à área de abrangência do empreendimento energético. No relatório daquele órgão indigenista foram reconhecidas as diversas comunidades Chiquitano com uma população estimada em 2400 indígenas.

O processo de reconhecimento oficial desses índios foi profundamente influenciado por instituições como a Igreja Católica tendo contado também com o apoio de diversos organismos não governamentais e representantes da sociedade civil organizada. São 4 as comunidades reconhecidas oficialmente: Vila Nova Barbecho, Acorizal, Central e Fazendinha. Na comunidade Central ficam sediados os Postos da Fundação Nacional do 
Índio, da Fundação Nacional de Saúde, a Escola Indígena Chiquitano ${ }^{1}$ e o Memorial Espírito Santo dos Chiquitanos. Segundo Santana (2012) o Memorial foi planejado para ser um espaço de referência para a comunidade, localizado simbolicamente em um antigo entroncamento onde passava a estrada Real do período colonial que ligava Vila Bela da Santíssima Trindade à capital Cuiabá. Essa escolha levou em conta o fato daquele lugar representar o despertar de um espaço tradicional, uma espécie de retomada dos caminhos, uma religação com a Coroa do Mundo (missão de Santa Ana) que era feita através da procissão em homenagem àquela santa. 0 Memorial é uma construção feita nos moldes das igrejas existentes nas missões jesuíticas da Bolívia. Ali são realizadas diversas atividades festivas escolares (dia do índio, dia das mães, dia das crianças etc.) e eventos comunitários (encontros, reuniões, cursos, treinamentos, etc.). A ideia da criação do Memorial partiu de conversas entre membros da comunidade e técnicos da FUNAI. Foi pensado como um espaço para a promoção da cultura Chiquitano, um importante espaço no processo de retomada dos valores étnicos ancestrais.

Durante muito tempo viveram o estigma de serem índios inventados, simples migrantes bolivianos que reivindicam a condição de indígenas para obter ajuda e alguma proteção do Estado brasileiro que possui uma política de proteção aos índios através de organismos como a FUNAI e a Fundação Nacional de Saúde- FUNASA. Hoje o Brasil os reconhece parcialmente como índios, pois recebem apoio de alguns organismos estatais, mas não o foi ainda inteiramente pela FUNAI, condição indispensável para um pleno reconhecimento étnico e acesso a bens e proteção oficial. Mas o cenário tanto do lado brasileiro quanto boliviano mudou bastante, hoje mais favorável do processo de afirmação étnica. No Brasil, desde a Constituição de 1988, não é mais adotado o paradigma evolucionista segundo o qual os índios "estavam" índios até que sua identidade indígena fosse dissolvida na massa geral da população. Na Bolívia, também importantes mudanças institucionais ocorreram no sentido do reconhecimento dos direitos coletivos das populações de origem ameríndia. Ambos os Estados adotam um caráter pluriétnico e multicultural.

7 Como explicar essa trajetória dos Chiquitano brasileiros? Trata-se de manipulação de camponeses reivindicando sua indianidade para obter benefícios e facilidades do das agencias oficiais do governo brasileiro? De equívocos de antropólogos, linguistas e historiadores bem-intencionados ao afirmarem a identidade indígena dessa população ? De um caso de emergência étnica? De desvelamento identitário? De resistência étnica? Ou de mais um caso de reinvenção de tradições e identidades?

8 Em nossa opinião, trata-se de um típico caso do que se convenciona chamar de etnogênese $e^{2}$, de um empreendimento identitário ${ }^{3}$ marcado pelo processo social de surgimento de grupos étnicos. E, a performance da festa de inauguração do Memorial por ser vista como mais um ato que revela esse processo, ao mesmo tempo que o reatualiza.

9 Advindos dos estudos culturais a partir do encontro entre diversas áreas do conhecimento, a concepção originária de performance veio do francês (parfournir) ${ }^{4}$, mas foi desenvolvida nas décadas de 30 e 40, com a chamada "virada dramatúrgica" que se espalhou nos Estados Unidos e em diversos setores dos estudos culturais. $O$ suíço Paul Zumthor (2007) considera a performance como algo marcado fortemente pela prática (em nosso caso, a festa), que se compõe por meio de materialidades em ato, constitutivas de uma forma força. Performance pode ser compreendida assim, como 
uma expressão cultural que se dá a ler por meio da forma : gestos, vocalidades, corpos em movimento que se movimentam em um espaço. Esse ato é da natureza teatral e se configura como jogo dinâmico e ritual, que instiga reconhecimentos, genealogias reatualizadas ou mesmo interações culturais situacionais. Ocorre em situação liminar, o que faz com que os sujeitos envolvidos sejam transportados e transformados pelo ato em jogo (SCHECHNER, 2011). A performance dos Chiquitano naquele dia da inauguração do Memorial chamou a nossa atenção para o temporário, para o estranhamento do cotidiano representado pelos cânticos em língua Chiquitano, a poética do momento único vivido pelos presentes, enfim, a negociação de expectativas e sensações dos atores em ação.

Da mesma maneira, os princípios da chamada etnogênese, podem ser elucidativos para o estudo de coletividades étnicas, em especial, as que se organizam depois de intensos processos de migração, diásporas, invasões, conquistas, fissões e fusões, como é o caso dos Chiquitano.

\section{Performances Etnogênicas e Identitárias}

11 No Brasil, sobretudo no Nordeste brasileiro, nos últimos anos, aumentou o número de populações que passam a reivindicar a condição de indígenas. Conforme Oliveira Filho (1998 : p. 47) na década de 1950 a relação de povos indígenas do Nordeste incluía cerca de 10 etnias ; quarenta anos depois, em 1994, essa lista subia para 23. Hoje, esse número ultrapassa mais de 26 povos. São famílias miscigenadas, mestiçadas, geralmente territorialmente espoliadas que reencontram contextos políticos e históricos favoráveis à luta por uma identidade coletiva indígena.

Oliveira Filho $(1998 ; 1990)$ em seus estudos sobre os indígenas do nordeste brasileiro e os processos de etnogênese ajuda-nos a melhor compreender os acontecimentos ocorridos entre os Chiquitanos. Contra uma espécie de etnologia das perdas esse autor propõe outra maneira de conceber as "etnogêneses" e demais processos identitários. Propõe perceber a existência de um fato histórico, a presença colonial (aldeamento, presídio, criação de reservas, postos indígenas, reconhecimento oficial das terras), que instaura uma nova relação da sociedade com o território (territorialização) deflagrando transformações em múltiplos níveis de sua existência sociocultural. A idéia de territorialização $0^{5}$ relaciona-se à etnicidade, que supõe uma trajetória que é histórica e determinada por muitos fatores, e uma origem que é uma experiência primária, individual, mas que também está traduzida em saberes e narrativas aos quais se acopla. o que seria próprio desses processos identitários, é que nos mesmos a atualização histórica não anula o sentimento de referência à origem, mas o reforça. $O$ autor usa a expressão "viagem de volta" para analisar processos de ressurgimento étnicos. Segundo Oliveira Filho, esse processo se dá através da elaboração de utopias religiosas, morais ou políticas.

13 Ao abordar os chamados processos de etnogênese, de emergência de novas identidades e também as reinvenções de etnias já reconhecidas, Oliveira Filho buscou historicamente o elemento responsável pela passagem de uma sociedade segmentar à condição de sociedade centralizada. Segundo o autor, o elemento responsável por tal transformação é a sua incorporação dentro de uma situação colonial sujeita a um aparato político-administrativo que integra e representa um Estado. Um fato histórico, a presença colonial que instaura uma nova relação da sociedade com o território, 
deflagra transformações em múltiplos níveis sócio-culturais. Esse processo de territorialização, definido como um processo de reorganização social implica na: 1criação de uma nova unidade sociocultural mediante o estabelecimento de uma identidade étnica diferenciadora; 2-constituição de mecanismos políticos especializados; 3- redefinição do controle social sobre os recursos ambientais; 4reelaboração da cultura e da relação com o passado.

Os aspectos de (re)atualização dinâmica dessas culturas estão intimamente ligados às maneiras como se relacionam com a sociedade nacional instituída e como performam a própria cultura. Como culturas híbridas, frutos de processos intensos de mobilidade e readaptações, essas culturas se situam em lugares intermediários, entrelugares só reconhecíveis de maneira performática. São identidades diferenciais que necessitam de regulação e negociação contínuas, em espaços intervalares. Para Homi Babbha, estas culturas forjam identidades diferenciais de natureza performática (BABBHA, 2005 : p. 301). A festa dos Chiquitano é, portanto, um local privilegiado de leitura e compreensão das dinâmicas etnogênicas dessa cultura, bem como um repertório cênico situacional, algo que interfere de maneira conjuntural nos processos etnopolíticos em ação.

Para os estudos da performance, a autenticidade das culturas só pode ser apreendida de maneira imaterial, na transitoriedade do instante e do acontecimento. Segundo João Gabriel Teixeira, essa autenticidade se baseia no momento de cada performance, conforme a intencionalidade de cada realização (TEIXEIRA, 2010: p. 47). Em estudos sobre preservação cultural, Teixeira defende a salvaguarda, não de uma identidade estática que tenha algum valor genético e de ancienidade, algo localizado em parâmetros originários, mas "em cada recriação singular e expressiva do aqui e agora" só possível por um ato performático, como a festa Chiquitano. Sob esta constatação, cabe aos poderes públicos garantir a liberdade de realização do ato performático que reatualiza e identifica essas culturas (TEIXEIRA, 2010 : p. 49).

As populações indígenas que hoje habitam o Nordeste brasileiro, assim como a população Chiquitano são oriundas de culturas autóctones que foram envolvidas em diferentes processos de territorialização. No caso dos índios do Nordeste brasileiro, um primeiro processo data do século XVI e XVII. Com poucos fluxos migratórios para o interior (sertão), antigas terras dos aldeamentos permaneceram sob o controle dos descendentes dos índios descidos para as missões que se identificavam coletivamente mediante referencias a missões e santos padroeiros. Até o século XVIII, a região nordestina contava com cerca de 60 aldeamentos, ocupados por aproximadamente 27 nações indígenas. Com a Lei de Terras de 1850 inicia-se um movimento de regularização das propriedades rurais. Em áreas de ocupação antiga como foi o caso do NE, as antigas vilas, progressivamente expandem o seu núcleo urbano e famílias buscam estabelecerse em terras dos aldeamentos como produtoras agrícolas. Paralelamente, os governos provinciais declaram extintos os antigos aldeamentos indígenas e incorporam os seus terrenos a comarcas e municípios recém-criados ${ }^{7}$. Ao mesmo tempo, pequenos agricultores e fazendeiros não-indígenas consolidam as suas posses dentro dos territórios dos antigos aldeamentos. Para Arruti (1996), essa última "mistura", a mais radical, limitou seriamente as posses por parte dos indígenas dos seus antigos territórios. Foi o que aconteceu, por exemplo, com o Pankararu do Brejo dos Padres. Desta forma, em fins do século XIX muitos povos indígenas do Nordeste haviam sido extintos ou invisibilizados (uma vez que muitos permaneceram na região, trabalhando 
para os novos donos, guardando na memória o tempo em que haviam sido espoliados de suas terras) por ação, omissão e até mesmo por decreto oficial. Os indígenas da região deixam então de serem reconhecidos como coletividades e passam a serem referidos na literatura como "remanescentes" ou "descendentes". Tornaram-se desta forma os chamados "índios misturados" dos documentos oficiais. Tornaram-se também, os remanescentes que haviam "perdido" praticamente todos os elementos diacríticos da cultura ameríndia "tradicional". A população regional e eles próprios passam a se referir a suas festas e crenças como "tradições populares", objeto da atenção de folcloristas. Um segundo processo de territorialização dos índios nordestinos ocorreu na década de 1920 com o reconhecimento oficial por parte do governo de Pernambuco das terras doadas ao antigo aldeamento missionário de Ipanema (1705), passando-as ao controle do SPI ${ }^{8}$ para que fosse dada assistência aos "remanescentes" dos Carnijos" até que fossem integrados à massa da população regional. ${ }^{9}$ Os Fulni-ô, como passaram a ser chamados esses índios, mantém até hoje sua língua (yatê) e um período de reclusão ritual (o "ouricouri"), constituindo-se assim como os mais "autênticos" índios da região. A ação do Estado reconhecendo um território foi fundamental na preservação dessa identidade indígena dos Fulniô. Esse ciclo, conforme Arruti (2009) se configurou com base em uma rede de relações previamente existente entre os grupos de 'caboclos ${ }^{10}$ e agentes externos, sucessivamente, da Igreja, da academia e do Estado. Criou-se assim uma espécie de efeito dominó, em que diversos "remanescentes" buscaram o reconhecimento e proteção oficial que, nesse caso, implicou na interrupção das violências sofridas por parte de grileiros e o acesso a bens materiais, como ferramentas, sementes e benfeitorias resultantes da proteção tutelar do Estado. Tais intervenções repercutiram sobre toda a região, despertando o interesse de uma série de outras comunidades de "caboclos" que viviam situação semelhante. Asssim, nas décadas seguintes foram reconhecidas como indígenas diversas populações do Nordeste. Em 1937 os Pankararu (Brejo dos Padres, PE) e os Pataxó, da Fazenda Paraguassu/Caramuru (Ilhéus, BA) ; em 1944 os Kariri-Xocó, da ilha de São Pedro (AL) ; em 1949 os Atikum, da serra do Umã (PE), e os Kiriri, de Mirandela (BA); em 1952 os Xukuru-Kariri, da Fazenda Canto (AL) ; em 1954 foi a vez dos Kambiwá (PE) ; em 1957 os Xukuru, de Pesqueira (PE). Na maior parte dos casos terras foram demarcadas e as populações passaram a contar com a proteção oficial por meio dos chamados Postos Indígenas do SPI. A cultura desses povos, afetadas pelos processos de territorialização vividos, submetidos a fortes pressões no sentido de uma assimilação quase compulsória é marcado por diferentes "fluxos" e "tradições". 0 ritual do toré gradativamente assume importante papel, pois permite exibir a todos os atores presentes nessa situação interétnica (regionais, indigenistas e os próprios índios) os sinais diacríticos de indianidade (OLIVEIRA, 1988). Outro movimento de territorialização ocorreu nos anos 1970/80. Povos como os Tinguí-Botó, os Karapotó, os Kantaruré, os Jeripancó, os Tapeba, os Wassu, passam a reivindicar sua indianidade. Entre 1977 e 1979, surgem cinco grupos reivindicando a identificação oficial como indígenas. Entre 1980 e 1989, surgem mais dez e, entre 1990 e 1998, mais nove. Não estão mais ligadas necessariamente às terras de antigos aldeamentos. No dizer de Arruti (2009) estão mais relacionados à constituição de um campo indigenista no Brasil, que tem como um dos seus principais atores a igreja católica, influenciada inicialmente pela chamada Teologia da Libertação. O Conselho Indigenista Missionário da Igreja Católica juntamente com as Associações de Apoio ao Índio (ANAI) e outras instituições não governamentais terão importante papel no apoio à luta pelo reconhecimento desses 
povos. Nesse terceiro momento, surgem povos que tiveram terras inundadas por barragens e que, como os Tuxá se partiram em outros dois grupos. Outros surgiram devido a rupturas faccionais que levaram a constituição de novas unidades sóciopolíticas para as quais passam a existir novas demandas territoriais e uma nova estrutura oficial, com novas lideranças reconhecidas pelo órgão, novo Posto Indígena. Há ainda os casos em que a há a reivindicação de uma identidade e de um etnônimo próprios pensados como parte desgarrada e autonomizada de unidades mais amplas, por efeito das migrações em busca de novas terras ou de água, tão comum entre as populações do sertão. Esse foi o caso de diversos grupos ligados aos Pankararu surgidos no período entre 1970 e 1995. Esses processos mais atuais estão ligados a uma nova realidade do Estado brasileiro. A Constituição de 1988 instaura um novo paradigma que rompe com o integracionismo e parte do pressuposto de que os índios não desaparecerão inexoravelmente face è "evolução da civilização". Com o novo texto constitucional, o Brasil passa a se definir gradativamente como um Estado pluriétnico e multicultural ${ }^{11}$.

17 No caso dos Chiquitanos, um primeiro processo de territorialização foi marcado pelas reducciones jesuíticas que forjou a identidade Chiquitana ainda do lado boliviano da fronteira ; um segundo momento seria marcado pelos diversos processos históricos que possibilitaram a diáspora desses campesinos para o Brasil. Aqui esses índios-imigrantes viveram um terceiro processo, marcado pela ação missionária da Igreja católica ligada e pela construção do Gaseoduto que criou as condições favoráveis para a cristalização da identidade Chiquitano e seu reconhecimento oficial. Esse processo foi ainda facilitado pelo novo paradigma adotado pelo Estado brasileiro em relação aos índios e que culminou com a Constituição de 1988 que ao adotar um caráter multiétnico pluricultural, sem dúvida favoreceu o empreendimento identitário daquele povo.

Como alertamos em outra ocasião (Rocha, 2010), as chamadas etnogêneses são parte do processo histórico da humanidade e não apenas um fenômeno contemporâneo. O Brasil, como outros países, tem sua história marcada por múltiplos processos de etnogênese que vem se formando tanto no passado como no presente, embora algumas momentos históricos sejam mais ou menos favoráveis a esses processo. Como exemplo de momentos mais favoráveis a esses processos, como chamamos a atenção anteriormente ${ }^{12}$, temos o fato do Estado se reconhecer como pluriétnico e multicultural (Constituição de 1988) ${ }^{13}$. Esses processos se inserem ainda nos contextos descrito por Sahlins (1997) como marcados pela capacidade indígena de reelaborar culturalmente suas histórias, mesmo a partir de situações que lhes são desfavoráveis. Povos antes subalternizados ou invizibilizados, antigas vítimas do colonialismo e do imperialismo, redescobrem sua cultura.

19 Há a tentação de se ver os grupos étnicos como simples derivação de etnias, isto é, como grupo de pessoas de uma mesma raça ou nacionalidade que apresenta uma cultura comum e distinta. Entretanto as etnias são definidas não tanto pelos conteúdos culturais, mas por formarem unidades sociais que emergem de mecanismos sociais de diferenciação de grupos em interação, o que remete aos modos particulares de construir oposições. Em uma analise situacional, a cultura se torna apenas uma variável que não explica, mas sim, é explicada pelos mecanismos delimitadores e definidores dos grupos. É por isso que o termo etnogênese nos remete aos mecanismos sociais que permitem que um grupo não apenas invente suas tradições, mas principalmente, de forma situacional, aos mecanismos sociais que possibilitam que um grupo social 
estabeleça o descontínuo onde antes, pelos menos aparentemente, havia a continuidade. Em outras palavras, compreender as razões, os meios e processos que levam ao reconhecimento das diferenças. No dizer de Arruti (2009), a etonogênese é o processo em oposição ao etnocídio, algo que contribui para a autoconsciência necessária à conformação de identidades intervalares, situacionais, mas que garantem conquistas coletivas. Como bem observa esse autor, uma vez reconhecidos e estabelecidos diante do movimento indígena, da sociedade e do Estado, esses grupos deixam a condição de emergentes ou remanescentes para integrarem-se à extensa lista das etnias brasileiras.

Os Chiquitano ilustram bem esse quadro. Independente de "como de fato foram" no passado, os laços das comunidades atuais com grupos do passado, precisam (e são) ser produzidos hoje e acontecem por meio da seleção e recriação de elementos da memória, de traços culturais que sirvam como os sinais externos reconhecidos pelos mediadores e pelos órgãos oficiais que tem a autoridade de nomeação. As diferenças que muitas vezes os distinguia da população local na forma de estigmas passam a ganhar positividade.

21 Os acontecimentos vividos por este povo são partes de grandes projetos identitários do mundo contemporâneo ${ }^{14}$. Reconhecer esse processo, ligado à plasticidade identitária que marca boa parte dessas comunidades, antes de vir a deslegitimar o lugar dos pretendentes, serve como um sinal de alerta para aqueles que operam na correlação de forças que definirá qual é este lugar e quais as formas de acesso a ele.

O suíço Paul Zumthor, admite que alguns traços são constitutivos da perspectiva performática em correlação com as identidades: sua capacidade de produzir reconhecimento, algo que faz passar da virtualidade à atualidade; seus aspectos situacionais como fenômenos culturais e situacionais, dente outros. Possuem também uma reiterabilidade dinâmica. São, ainda, de natureza cognitiva, pois atos performáticos transmitem, ao mesmo tempo que afetam o conhecido (ZUMTHOR, 2007 : p.32). A teatralidade fruto da movimentação dos corpos no espaço festivo, seu repertório ensaiado e seletivo, suas músicas e encenações de histórias tradicionais, podem ser encaradas como um mosaico híbrido em circularidade cultural. Cada gesto, movimento, instrumentos utilizados, ou mesmo as performances orais e poéticas, são frutos de uma circularidade hermenêutica em que a facticidade das origens se rearticula e se reconhece, ao mesmo tempo em que age e se modifica. Em oposição poético cultural, elementos díspares se combinam e performam em um novo arranjo. A flauta e o tambor, a missa e o hino Chiquitano, o idioma nativo combinado ao alfabeto experimental dos antropólogos e linguistas, o colar de sementes e o crucifixo. Paradoxos antitéticos que nos remetem ao cadinho da hibridização que deseja se estabelecer com singularidade, para se diferenciar, recontar e atualizar reinvenções. A performance em ato tem o poder da agoridade, pois coloca performers e espectadores no jogo cênico, um ato educativo, conformador de identidades em ação.

No caso da identidade Chiquitana é a agency - ou intencionalidade e ação estratégica bem-sucedida - dos oprimidos e sua sabedoria cosmopolita que ditarão o rumo dos acontecimentos. Nesse sentido a história dos Chiquitano guarda similaridades com os processos descritos por J. Lorand Matory (1999) ao analisar a nação Jeje com produto direto da diáspora africana. Esse autor afirma que muitas nações de origem africana foram freqüentemente agrupamentos impostos a diversos povos e a distintas ordens de categorias políticas, lingüísticas e culturais unificados primariamente para os propósitos dos comerciantes de escravos. Um grande trabalho cultural e institucional 
os amalgamou em nações. Uma parte desse trabalho teria sido feita pelos donos de escravos e pela Igreja Católica. Alguns grupos étnicos foram preferidos em detrimentos de outros. Os projetos de evangelização da Igreja Católica geraram irmandades que ajudaram enormemente na afirmação dessas identidades. Para esse autor, a agency, ou a intencionalidade e ação estratégica bem-sucedida dos oprimidos e sua sabedoria cosmopolita forjaram nos viajantes afro-brasileiros, novas formas de solidariedade transregionais e transoceânicas, demonstrando assim que as comunidades diaspóricas, poderosamente imaginadas, desenvolviam-se paralelamente à nação territorial. Seria esse o caso dos Chiquitanos ? Poderíamos considerá-los como comunidades diaspóricas poderosamente imaginadas em uma região transfronteiriça entre o Brasil e a Bolívia ? Certamente que sim.

\section{O Paradoxo Verger / Bastide e o Historiador Cultural como Co-fundador de Identidades em Jogo}

Outro ponto importante para o entendimento dos processos identitários dos Chiquitano e o jogo performático que empreendem na festa e em outros atos dessa natureza, é explorar o lugar do antropólogo/historiador/pesquisador: a) como um lugar social negociado na situação de investigação a partir da qual se pode conceber o engajamento crítico do pesquisador; b) como lugar intelectual no sentido de que o antropólogo/ historiador tem necessidade de ferramentas teóricas atualizadas para dar conta da relação contemporânea entre identidade e cultura ${ }^{15}$. Ao mesmo tempo em que as ciências sociais desconstruíram um objeto que havia sido por muito tempo tratada como essencialista, as sociedades o reconstruíram em seus próprios mundos e, geralmente segundo essa modalidade afirmando seu caráter absoluto, autêntico e atemporal. Outra questão, portanto, precisa ser abordada em relação a esses processos identitários contemporâneos. Trata-se do chamado paradoxo Bastide e Verger ${ }^{16}$. Esses antropólogos ao produzirem suas descrições etnográficas sobre populações negras na Bahia no início do século XX foram como bem observou Agier (2001) vetores de globalização cultural e etnização local, pois contribuíram para a desterritorialização da África e a transformação da África em universo particularizável fazendo com que a África tenha se tornado um vasto caldeirão cultural mestiço. Para desenvolver seu argumento, Agier nos conta uma pequena história, a de um conhecido bloco carnavalesco baiano, o Ilê Aihê. Ao estudar nos anos 1990 a africanização do carnaval o autor reconstitui a trajetória desse grupo baiano. Constatou existirem duas histórias : uma oficial, essencialista que liga a origem do Ilê Aihê a um terreiro de candomblé ; e aquela fruto da pesquisa, que recupera outra história apagada ou pouco enfatizada pela memória coletiva do grupo. Pela segunda versão, tudo começou com um presente dado por um engenheiro europeu de um livro escrito à mão existente na biblioteca da Universidade Federal da Bahia. O livro intitulado Yoruba tal qual se fala, foi originalmente escrito à mão por Descóredes Maximiliano dos Santos (mestre Didi, erudito do candomblé, filho de mãe Senhora, antiga mãe de santo do terreiro Axé Opo Afonjá, considerado ortodoxo quanto às tradições e amigo de etnólogos como Verger e Bastide). $O$ autor lembra que o próprio Descoredes Santos havia sido socializado em posições já adquiridas no universo afro-brasileiro marcado por estratégia identitárias inovadoras e tradicionalistas. O mesmo foi o fundador da Sociedade de Estudos da Cultura Negra em 1974, contemporâneo da fundação do bloco Ilê Ayhé. Lembra ainda 
que a mãe de um dos pesquisados do Ilê Ayhê dirigia um terreiro de candomblé onde foi instalada a sede do grupo, ou seja, seus pesquisados estavam fabricando uma tradição. o que esse autor ressalta, portanto, é que os antropólogos e historiadores, em uma analise situacional, devem levar em conta em uma visão não essencialista dos processos identitários, não só o papel de agentes dos atores em situação, como o próprio papel dos antropólogos, historiadores, sociólogos e linguistas que, ao descreverem, ao elaboraram em suas etnografias, teses e dissertações forjam o retrato de uma determinada cultura numa postura não essencialista, mas paradoxalmente ajudam a essencializar seus traços e, muitas vezes inconscientemente, ajudam a fundar identidades.

Teria Yara Penteado, Giovani Silva, Aurea Santana e outros pesquisadores que estudaram os Chiquitano brasileiros, por exemplo, vivido o paradoxo de Verger e Bastide? Certamente o assessoramento linguístico de Áurea Santana no projeto de revitalização da língua e cultura dos Chiquitana e as atividades culturais promovidas pela Escola no Memorial são parte importante nesse processo.

\section{Considerações Finais}

Os povos indígenas hoje estão tão distantes de suas culturas ancestrais, quanto qualquer outro povo ainda que certamente existam pontos de continuidade histórica unindo-os aos seus ancestrais, ao seu passado. O fenômeno de surgimento ou de redescoberta de comunidades ditas remanescentes de indígenas corresponde à produção de novos atores políticos resultantes de processos de reforço e potencialização da alteridade. Esse fenômeno significa para essas populações a possibilidade de ocupar um lugar novo e diferenciado em relação ao restante da sociedade, na política regional ou mesmo diante do Estado. Significa também para esses povos, a busca por um novo lugar no imaginário nacional e em seu próprio imaginário. Para Sahlins (1997) a cultura funciona como uma síntese de estabilidade e mudança, de passado e presente, de diacronia e sincronia. Toda mudança também é reprodução cultural. Esse poder de transformação que os "signos em ação" têm, são decorrentes do que Sahlins denomina como "estrutura da conjuntura" que consiste no conjunto das relações históricas que a um só tempo, podem produzir categorias culturais tradicionais ou atribuir-lhes novos valores a partir do que exige o contexto. A trajetória dos Chiquitano segue uma lógica semelhante à de inúmeros outros povos indígenas : em alguns momentos históricos desfavoráveis foram sendo apagados e invisibilizados, diluídos entre esquecimentos e preconceitos. Em outros momentos encontram condições favoráveis para a constituição e consolidação de suas identidades.

As discussões aqui propostas buscaram articular em sua trama uma análise situacional levando em conta a pluralidade dos atores envolvidos, suas performances, resgatando as formas de organização, os valores, as ideologias, as representações, manipulações e estratégias de ação colocadas em prática por cada um desses atores em diferentes momentos de sua história, captando as diferentes significações que cada ator atribui às situações vividas bem como o modo pelo qual as codifica e sistematiza. Enfim, captar a dinâmica dos processos vistos como partes de uma complexa rede de interações sociais. Essas dinâmicas, podem ser lidas por meio dos agenciamentos performáticos presentes em movimentos culturais situacionais, como a festa, uma espécie de âncora que nos ajuda a ler identidades, ao mesmo tempo que nos coloca em jogo com o ato 
dramatúrgico etnogênico, materialidade cênica que contribui para os agenciamentos políticos identitários. $\mathrm{O}$ enfoque performático que utilizamos neste artigo enfatizou a identidade Chiquitana exposta e ostentada publicamente em eventos rituais ou políticos através da recriação de tradições e, sua relação com movimentos de etnogênese e afirmação étnicas em situações conflituosas.

\section{BIBLIOGRAFIA}

AGIER, Michel. Distúrbios identitários em tempos de globalização. IN : Mana 7(2) :7-33, 2001.

ARRUTI José Maurício Andion. Etnogêneses Indígenas. IN : http://www.socioambiental.org.br/. Acessado em 19 out/ 2009.

ARRUTI, José Maurício Andion. O Reencantamento do Mundo - Trama Histórica e Arranjos Territoriais Pankararú. Rio de Janeiro, PPGAS-MN-UFRJ. 1996. Dissertação de mestrado.

ARRUTI, José Maurício Andion. "Por uma História a Contra luz : As Sombras Historiográficas, as Paisagens Etnográficas e o Mocambo”. Palmares em Revista no. 1, 1996, pp. 71-96.

BABBHA, Homi. O Local da Cultura. Belo Horizonte: Ed. UFMG, 2005.

MATORY. J. Lorand. Jeje : repensando nações e transnacionalismo. In: MANA 5(1) :57-80, 1999.

OLIVEIRA FILHO, João Pacheco (Org.). A Viagem da volta - Etnicidade, política e reelaboração cultural no nordeste indígena. Rio de Janeiro : Contra Capa Livraria, 1999.

OLIVEIRA FILHO, João Pacheco de. Uma etnologia dos “índios misturados” ? Situação colonial, territorialização e fluxos culturais. In : Mana 4(10 : 41-77,1998).

ROCHA, Leandro M ; BITTENCOURT, Libertad B. Indigenismo e Participação Política na América Latina. Goiânia, Editora UFG, 2007.

ROCHA, Leandro M. A política Indigenista no Brasil : 1930-1967. Goiânia, Ed. UFG, 2003.

ROCHA, Leandro M. O Estado e os índios : Goiás 1850-1889. 1. ed. Goiânia : Editora da UFG, 1998. 120 p.

ROCHA, Leandro M. Etnicidade, identidade e fronteiras políticas : processos de etnogênese no Brasil contemporâneo. In: José Maria Rodrigues (Org.) Lenguas y culturas em el MERCOSUR: Pluralidad cultural e inclusión social en Brasil y en Paraguay. Assuncion: Centro de Postgrado e Investigación Universidad Católica Nuestra Señora de la Asunción, 2010. P. 59-80.

SAHLINS, M. Ilhas da História. Rio de Janeiro : Zahar, 1997.

SANTANA, Áurea Cavalcante. Línguas cruzadas, histórias que se mesclam : ações de documentação, valorização e fortalecimento da língua chiquitano no Brasil. Goiânia : Universidade Federal de Goiás, Maio de 2012 (tese de doutoramento).

SILVA, Giovani José. A presença Camba-chiquitano na fronteira Brasil-Bolívia (1938-1987) : identidades, migrações e práticas culturais. Goiânia, 2009. Tese de doutoramento em história.

SILVA, R. H. Brasileiro, bolivianos ou indígenas ? Construções identitárias dos Camba no Brasil, Niterói, UFF, 2009. Tese de doutoramento em antropologia. 
SCHECHNER, Richard. Performers e Espectadores - Transportados e Transformados. Revista Moringa. João Pessoa, vol. 2, n.1, 155-185, jan./jun. de 2011.

TEIXEIRA, João Gabriel \& VIANA, Letícia C.R (orgs.) Artes Populares no Planalto Central. Performance e Identidade. Brasília, Verbis Editora, 2010.

ZUMTHOR, Paul. Performance, Recepção e Leitura. São Paulo : Cosac Naify, 2007.

\section{NOTAS}

1. As Escolas Indígenas, por força legal, são diferenciadas contando com calendário e conteúdos próprios e diferentes das demais escolas. Embora sejam mantidas por estados e municípios, são reguladas por legislação específica federal.

2. Mais recentemente, o termo tem sido utilizado para dar conta dos processos de emergência social e política dos grupos tradicionalmente submetidos a relações de dominação. São designações alternativas ao termo, as "emergências", "ressurgimentos", ou "viagens da volta". Trata-se, portanto, de um termo, conceitualmente controverso usado para descrever a constituição de novos grupos étnicos.

3. Sobre o termo Empreendimento Identitário, ver Agier (2001).

4. Parfounir : palavra que nos remete ao sentido geral de ação (ou processo de agir) executada com determinado fim. Do francês antigo parfounir (realizar, consumar), combina o prefixo latino per (indicativo de intensidade), com fournir (de provável origem germânica) que significa prover, providenciar, fornecer (em inglês, fournish).

5. Oliveira Filho (1998) chama de processo de territorialização o movimento pelo qual um objeto político-administrativo - nas colônias francesas seria a "etnia", na América espanhola as "reducciones" e "resguardos", no Brasil as "comunidades indígenas" - vem a se transformar em uma coletividade organizada, formulando uma identidade própria, instituindo mecanismos de tomada de decisão e de representação, e reestruturando as suas formas culturais (inclusive as que o relacionam com o meio ambiente e com o universo religioso.

6. Uma carta ao Presidente da FUNAI ou outra autoridade governamental feita pelas lideranças pode ser vista como um exemplo que como se articula essa volta. A construção da escola ou do Memorial, fruto do diálogo com autoridades ou e interlocuções com antropólogos, historiadores ou outro interlocutor externo, esperando poder ter sua etnicidade oficialmente reconhecida poderia ser interpretada como essa "viagem de volta".

7. Ver sobre a política indigenista no século XIX, Rocha (1998).

8. O Serviço de Proteção aos Índios, organismo responsável pela proteção e assistência aos índios, foi criado em 1910 e foi substituída pela Fundação Nacional do Índio em 1967.

9. Essa política baseava-se no paradigma evolucionista da integração segundo a qual cabia ao Estado gerir o processo considerado inexorável de transformação do índio brasileiro. Ver sobre esse tema : Rocha (2003).

10. O termo caboclo é comumente utilizado para referir-se às populações camponesas dos sertões, muitas destas mestiças descendentes de índios e negros.

11. Da mesma forma, e como parte dessas transformações paradigmáticas do Estado brasileiro, as mudanças introduzidas no ordenamento jurídico nacional, decorrentes da ratificação pelo governo brasileiro da Convenção n⿳o 169 sobre "Povos Indígenas e Tribais em Países Independentes", da Organização das Nações Unidas (ONU) de 1989, trouxeram, por facilitar tais processos, consequências importantes para as dinâmicas sociais envolvidas nesses processos de etnogênese.

12. Ver ROCHA (2010). 
13. Sobre a história da política indigenista brasileira contemporânea e esse aspecto da Constituição de 1988, ver : Rocha ; Bittencourt (2007).

14. Como observa Agier (2001), as evoluções sociais e políticas das ultimas décadas impõem um objeto empírico relativamente novo para a antropologia e para a história, o dos grandes empreendimentos identitários que tendem a substituir antigas tribos, aldeias perdidas e outras etnias por atitudes de retorno, recolhimento identitário, inovações, invenções, mestiçagem e uma grande abertura para o presente. Para Agier a importância está em reconhecer o seu lugar, ainda que mal definido tanto com relação às condições de acesso aos seus novos direitos, quanto às condições de exercício de sua nova identidade. Por sua vez, a definição mais favorável daquilo que devem ser não depende apenas deles ou dos seus opositores, mas também do estado da correlação de forças em que aquelas comunidades e seus mediadores estão inseridos e na qual o papel interpretativo do antropólogo, do linguista e do historiador se destaca.

15. AGIER (2001).

16. Pierre Edouard Leopold Verger (1902-1996) fotógrafo e etnólogo autodidata franco-brasileiro cujas contribuições para a etnologia são constituidas por diversas conferências, artigos de diário e livros que se tornaram uma referencia para os estudos sobre os afro-brasileiros. Roger Bastide (1898-1974) sociólogo francês que em 1938 integrou a missão de professores franceses na recémcriada Universidade de São Paulo tendo se tornado um dos grandes especialistas em religiões afro-brasileiras.

Sobre os autores : Leandro Mendes Rocha é Pós Doutor em História pela Universidade de La Rochelle (França) e professor do Programa de Pós-Graduação em História (PPGH) e do Núcleo Takinahaky de Formação de Professores Indígenas da Universidade Federal de Goiás (UFG). Heloisa Selma Fernandes Capel é Doutora em Educação, atua na linha de pesquisa Fronteiras, Interculturalidades e Ensino do PPGH em História (UFG).

\section{RESUMOS}

Este artigo explora as composições culturais híbridas dos Chiquitano, povo indígena da região fronteiriça entre Brasil e Bolívia, consubstanciadas em uma festa etnogênica, a Festa de inauguração do Memorial Espírito Santo dos Chiquitano, na qual processos identitários contemporâneos são reconhecidos e agenciados. Para tanto, inspira-se nas concepções dinâmicas da cultura advindas dos estudos culturais e dos estudos da performance, compreendendo a festa como ato cênico privilegiado, em que tradições são reatualizadas e reconhecidas em um espaço tempo liminar e situacional, bases cognitivas de um saber que envolve corpos em movimento e ação no espaço intercultural. São intencionalidades fantasmáticas em jogo que envolvem o ato performático agenciador e o historiador cultural, pesquisador participante.

Cet article explore les compositions hybrides culturelles des Chiquitano, populations de la région frontalière entre le Brésil et la Bolivie, incarnées dans une fête vue comme partie d'un processus d'ethnogenèse, l'inauguration du Mémorial Esprit Saint Chiquitano, dans lequel les processus identitaires contemporains sont reconnus. Cette étude s'appuie sur les conceptions dynamiques de la culture issues des études culturelles et de performance, comprenant la fête en tant qu' acte scénique. Ces traditions mises à jour dans un temps et un espace liminal, sont des bases cognitives de la connaissance, des corps en mouvement et de l'action dans l'espace interculturel. 
Ce sont des actions intentionnelles conduisant à des actes performatifs entre les acteurs sociaux et les historiens de la culture en tant qu'observateurs participants.

\section{ÍNDICE}

Palavras-chave: festa Chiquitano, etnogênese, interculturalidade, performance, estudos culturais

Mots-clés: fête Chiquitano, ethnogenèse, interculturalité, performance, études culturelles

\section{AUTORES}

\section{LEANDRO MENDES ROCHA}

Programa de Pós-Graduação em História/ UFG

leandromrocha[at]uol.com.br

\section{HELOISA SELMA FERNANDES CAPEL}

Programa de Pós-Graduação em História/ UFG

hcapel[at]gmail.com 